\title{
Integrin-linked kinase, a novel component of the cardiac mechanical stretch sensor, controls contractility in the zebrafish heart
}

\author{
Garnet Bendig, ${ }^{1,4}$ Matthias Grimmler, ${ }^{2,4}$ Inken G. Huttner, ${ }^{1}$ Georgia Wessels, ${ }^{1}$ Tillman Dahme, ${ }^{1}$ \\ Steffen Just, ${ }^{1}$ Nicole Trano, ${ }^{1}$ Hugo A. Katus, ${ }^{1}$ Mark C. Fishman, ${ }^{3}$ and Wolfgang Rottbauer ${ }^{1,5}$ \\ ${ }^{1}$ Department of Medicine III, University of Heidelberg, D-69120 Heidelberg, Germany; ${ }^{2}$ Department of Biochemistry, \\ Biocenter at the University of Würzburg, D-97074 Würzburg, Germany; ${ }^{3}$ Cardiovascular Research Center, Massachusetts \\ General Hospital and Department of Medicine, Harvard Medical School, Boston, Massachusetts 02114, USA
}

\begin{abstract}
The vertebrate heart possesses autoregulatory mechanisms enabling it first to sense and then to adapt its force of contraction to continually changing demands. The molecular components of the cardiac mechanical stretch sensor are mostly unknown but of immense medical importance, since dysfunction of this sensing machinery is suspected to be responsible for a significant proportion of human heart failure. In the hearts of the ethylnitros-urea (ENU)-induced, recessive embryonic lethal zebrafish heart failure mutant main squeeze (msq), we find stretch-responsive genes such as atrial natriuretic factor (anf) and vascular endothelial growth factor (vegf) severely down-regulated. We demonstrate through positional cloning that heart failure in msq mutants is due to a mutation in the integrin-linked kinase (ilk) gene. ILK specifically localizes to costameres and sarcomeric Z-discs. The msq mutation (L308P) reduces ILK kinase activity and disrupts binding of ILK to the $Z$-disc adaptor protein $\beta$-parvin (Affixin). Accordingly, in $m s q$ mutant embryos, heart failure can be suppressed by expression of ILK, and also of a constitutively active form of Protein Kinase B (PKB), and VEGF.

Furthermore, antisense-mediated abrogation of zebrafish $\beta$-parvin phenocopies the msq phenotype. Thus, we provide evidence that the heart uses the Integrin-ILK- $\beta$-parvin network to sense mechanical stretch and respond with increased expression of ANF and VEGF, the latter of which was recently shown to augment cardiac force by increasing the heart's calcium transients.
\end{abstract}

[Keywords: Integrin-linked kinase (ILK); zebrafish; cardiac stretch sensor; $\beta$-parvin (Affixin)]

Supplemental material is available at http://www.genesdev.org.

Received May 9, 2006; revised version accepted July 7, 2006.

The vertebrate heart possesses a unique autoregulatory mechanism enabling it to adapt its force of contraction to continually changing demands. On a beat-to-beat basis, the heart can adapt to changes in blood pressure or volume load. Chronic overload induces long-term changes that augment contractile force by assembly of additional myofibrils, with consequent cardiac hypertrophy. These adaptive responses of the heart are preceded by the sensing of biomechanical strain (mechanosensing) and transduction of these signals (mechanotransduction). Mechanical stretch of cardiomyocytes activates several signaling pathways, including mitogenactivated protein (MAP) kinases, JAK-STAT, and phosphatidylinositol 3-kinase (PI3K)-AKT (Pan et al. 1999;

\footnotetext{
${ }^{4}$ These authors contributed equally to this work.

${ }^{5}$ Corresponding author.

E-MAIL wolfgang.rottbauer@med.uni-heidelberg.de; FAX 49-6221-564866. Article published online ahead of print. Article and publication date are online at http://www.genesdev.org/cgi/doi/10.1101/gad.1448306.
}

Seko et al. 1999; Kim et al. 2002), ultimately inducing the expression of various cardiac stretch-responsive genes, such as atrial natriuretic factor (anf) and vascular endothelial growth factor (vegf) (Kim et al. 2002). However, most of the molecular components of the mechanical stretch sensor that trigger these cascades in the heart are still unknown. They are additionally of great clinical importance, because these mechanisms are part of the adaptive response to cardiac disease and of heart failure. In fact, dysfunction of components of the cardiac stress sensor system, including $\beta$-integrins, the integrin-interacting protein Melusin, or the Z-disc protein Muscle lim protein (MLP), can cause heart failure (Shai et al. 2002).

Integrin-linked kinase (ILK), an evolutionarily highly conserved serine/threonine (Ser/Thr) protein kinase, is expressed at high levels in cardiac and skeletal muscle, where it interacts with the cytoplasmic domain of $\beta 1$ Integrin (Hannigan et al. 1996). ILK contains three identifiable structural features, an ankyrin repeat region at 
its $\mathrm{N}$ terminus, followed by a phosphoinositide-binding motif (pleckstrin homology $[\mathrm{PH}]$ domain), and a C-terminal kinase domain (Delcommenne et al. 1998). ILK phosphorylates substrates such as Myelin basic protein (MBP) in vitro, and induces phosphorylation of Myosinlight chain-2, as well as the protein kinases GSK-3 $\beta$ and Protein Kinase B (PKB) in vivo (Delcommenne et al. 1998). Via PKB phosphorylation, ILK controls vegf transcription (Tan et al. 2004). ILK kinase activity is stimulated by VEGF and other growth factors, as well as by attachment of cells to the extracellular matrix (Attwell et al. 2003). To date, a large number of proteins have been identified that bind to different domains of ILK. At least five different proteins bind to the C-terminally located kinase domain: the transmembrane receptor protein $\beta 1$-Integrin, the adaptor proteins $\alpha$-parvin $(\mathrm{CH}$ ILKBP, Actopaxin), $\beta$-parvin (Affixin), Paxillin, and the catalytic protein PKB. The adaptor protein $\mathrm{PINCH}$ and the G-actin sequestering peptide Thymosin- $\beta 4$ interconnect with the $\mathrm{N}$-terminal ankyrin repeat domain of ILK (Bock-Marquette et al. 2004). Lack of ILK expression in Drosophila melanogaster and Caenorhabditis elegans results in severe muscle abnormalities (Zervas et al. 2001; Mackinnon et al. 2002), whereas mice lacking ILK expression die shortly after implantation, indicating an essential role of ILK in early embryonic development of vertebrates. However, the structural and functional roles of ILK in the vertebrate heart are still unknown.

To identify novel molecular components of the cardiac stretch sensor, we have assayed here the cardiac expression of anf and vegf in recessive embryonic lethal zebrafish heart failure mutants (T. Dahme, I.G. Huttner, and W. Rottbauer, unpubl.). Both anf and vegf were found to be significantly down-regulated in the hearts of the zebrafish mutant main squeeze ( $m s q$ ). By positional cloning we show that msq mutants carry a mutation in the zebrafish integrin-linked kinase (zilk) gene, which specifically disrupts ILK kinase activity and ILK- $\beta$ parvin binding. Heart contractility of homozygous mutant $m s q$ embryos can be restored by ectopic expression of constitutively active PKB or wild-type VEGF, and morpholino-modified antisense oligonucleotide mediated knockdown of zebrafish $\beta$-parvin phenocopies the $m s q$ heart phenotype. Taken together, our findings indicate that ILK, via interaction with Integrin and $\beta$-parvin, acts as an essential component of the cardiac stretch sensor to control transcription of the stretch-responsive genes anf and vegf and cardiac contractility.

\section{Results}

Stretch-responsive genes anf and vegf are severely down-regulated in zebrafish main squeeze (msq) hearts

To identify novel genetic components of the cardiac stretch sensor, we screened numerous ethylnitros-urea (ENU)-induced recessive, embryonic lethal zebrafish heart failure mutants (Stainier et al. 1996) for altered cardiac expression of the stretch-responsive genes anf and vegf, using whole-mount RNA antisense in situ hy- bridization and real-time PCR (T. Dahme, I.G. Huttner, and W. Rottbauer, unpubl.). In the hearts of the zebrafish mutant main squeeze $\left(m s q^{m 347}\right)$, we found both anf (Fig. 1C-F) and vegf severely down-regulated at $72 \mathrm{~h}$ postfertilization (hpf).

$m s q$ mutant embryos display progressive reduction of cardiac contractility. Aside from pericardial edema, $m s q$ embryos are not noticeably affected by the lack of normal blood flow during the first week of development (Fig. 1A,B). As in wild-type embryos, the two heart chambers-atrium and ventricle-contract rhythmically, sequentially, and vigorously in $m s q$ mutant embryos by $36 \mathrm{hpf}$. However, by $72 \mathrm{hpf}$, ventricular contractility of $m s q$ mutant embryos decreases progressively: fractional shortening of the $m s q$ ventricular chamber declines from $20.9 \pm 4.9 \%$ at 48 hpf to $1.5 \pm 3.26 \%$ at 72 hpf, and by $96 \mathrm{hpf}$, the ventricular chamber becomes completely silent (Fig. 1G,H; Supplementary Movie 1).

To determine whether the $m s q$ heart contractility defect is due to abnormal growth of ventricular cardiomyocytes as observed for the zebrafish mutants island beat (Rottbauer et al. 2001) and liebeskummer (Rottbauer et al. 2002), or due to disturbed cardiomyocyte myofibrillogenesis, as observed in the mutants pickwik (Xu et al. 2002), silent heart (Sehnert et al. 2002), or tell tale heart (Rottbauer et al. 2006), we analyzed the msq mutant hearts structurally and ultrastructurally. As in the wild type, embryonic heart morphogenesis proceeds normally in $m s q$ mutant embryos. By 72 hpf, $m s q$ mutant ventricles are structurally indistinguishable from wild-type hearts: A myocardial as well as an endocardial layer is clearly present, and the ventricular myocardium has thickened properly by addition of myocardial cells. The number of $m s q$ ventricular cardiomyocytes $(330 \pm 10$ SEM) is indistinguishable from wild type (340 \pm 22 SEM) (Fig. 1I,J), and there is no increase in the number of apoptotic myocardial cells compared with wild-type embryos assayed by TUNEL staining (data not shown). By whole-mount immunofluorescence, we investigated the expression of thick and thin filament sarcomeric proteins in wild-type and $m s q$ mutant embryos. Sarcomeric atrial and ventricular myosin heavy chain as well as sarcomeric actin protein expression is normal in $m s q$ mutant hearts (data not shown). Transmission electron microscopy of $m s q$ hearts after $72 \mathrm{hpf}$ reveals a normal architecture of ventricular cardiomyocytes, including regular arrays of thick and thin myofilaments, Z-discs, and intercalated discs, as well as normal content and appearance of mitochondria (Fig. 1K,L). These findings indicate that $m s q$ does not disrupt key steps in zebrafish heart morphogenesis or myocardial myofibrillogenesis, but rather interferes with an as-yet-unknown essential functional component of the contractile machinery.

\section{The main squeeze $\left(\mathrm{msq}^{\mathrm{m} 347}\right)$ locus encodes zilk}

We identified the ENU-induced mutation causing the recessive $m s q$ mutant phenotype by a positional walk (Fig. 2A). By bulk segregant analysis, we mapped msq to zebrafish linkage group 10. Recombination analysis of 




Figure 1. Effects of the $m s q^{\mathrm{m} 347}$ mutation on heart function, morphology, and expression of anf. $(A, B)$ Lateral view of wildtype (wt) $(A)$ and $m s q$ mutant embryos $(B)$ at $72 \mathrm{hpf}$. $m s q$ mutants develop pericardial edema due to loss of ventricular contractility, whereas the development of other organ systems proceeds normally. $(C-F)$ RNA levels of the stretch-responsive gene zanf are severely reduced in $m s q$ mutant hearts. In contrast to wild-type hearts, where robust expression of zanf throughout the heart can be observed at $48 \mathrm{hpf}(C)$ and $72 \mathrm{hpf}(D)$, zanf expression in $\mathrm{msq} \mathrm{mu}-$ tant hearts is only slightly reduced at 48 hpf $(E)$, but completely absent by $72 \mathrm{hpf}$ $(F)$. Atrium (A) and ventricle $(\mathrm{V})$ are indicated. $(G, H)$ Contractility of ms $q$ mutant zebrafish embryo ventricles severely decreases over time; by $96 \mathrm{hpf}$, the ventricular chamber becomes completely silent. Measurements of fractional shortening (FS) - an indicator of systolic contractile function normalized to the diameters of the heart-are displayed for the ventricular chamber of wild-type zebrafish embryos $(G)$ and $m s q$ mutants $(H)$ at different time points. $(I, J)$ The $m s q$ mutation does not affect overall heart morphology. Hematoxylin/eosin-stained histological sections of wild-type $(I)$ and $m s q$ mutant $(J)$ heart at $72 \mathrm{hpf}$. Endocardial (en) and myocardial (my) layers of ventricle and atrium of msq mutant heart are unaltered. $(K, L)$ Transmission electron microscopy of wildtype $(K)$ and $m s q$ mutant $(L)$ zebrafish embryonic hearts at $72 \mathrm{hpf}$. Ventricular cardiomyocytes of $m s q$ mutants show normal cell architecture and organization of myofibrils. Insets display transverse sections of myofilaments.
$1674 \mathrm{msq}$ mutant embryos restricted $\mathrm{msq}$ to a genomic interval flanked by the microsatellite markers z7504 and z7028 (Fig. 2A). According to genomic sequence alignment (BLASTX), the physical contig covering the ms $q$ locus contains three ORFs encoding proteins highly homologous to human ILK, Sphingomyelinase, and an asyet-unknown protein (GenBank accession no. Riken 2210415M20).

To identify the site of the ENU-induced mutation in $m s q$, we sequenced the entire zebrafish coding sequences of the three ORFs from wild-type and $m s q$ mutant cDNA and gDNA. Sequencing of neither the zebrafish sphingomyelinase nor Riken 2210415M20 coding sequence revealed a mutation in $m s q$ mutant cDNA. However, we identified the $m s q$ mutation to be a thymine-to-cytosine nucleotide transversion (CTA $\rightarrow$ CCA) in codon 308 of the zilk gene, predicted to change the highly conserved amino acid leucine to proline (L308P) (Fig. 2B). zilk is endcoded by 11 exons. The protein consists of 452 amino acids and shows $86 \%$ amino acid iden- tity to human and mouse ILK. As in other species, zILK contains at its N-terminal four ankyrin (ANK) repeats, followed by a $\mathrm{PH}$ domain and a kinase catalytic domain (amino acids 192-420), where the msq mutation (L308P) resides (Fig. 2C).

Injection of morpholino-modified antisense oligonucleotides against zilk phenocopies the msq heart phenotype

To confirm that the $m s q$ mutant heart phenotype is caused by disturbed zILK function, we injected morpholino-modified antisense oligonucleotides, either directed against the translational start site (MO1-zilk) or the splice donor site of exon 4 (MO2-zilk) of zilk into onecell-stage wild-type zebrafish embryos. When injecting either $4.2 \mathrm{ng}$ of MO1-zilk or $2.5 \mathrm{ng}$ of MO2-zilk, up to $87 \%$ of injected embryos (59 out of 68 for MO1-zilk and 85 out of 119 for MO2-zilk) display the msq mutant heart phenotype (Fig. 3A-C). Similar to msq mutant embryos, in MO1-zilk- and MO2-zilk-injected embryos the 
Bendig et al.

A

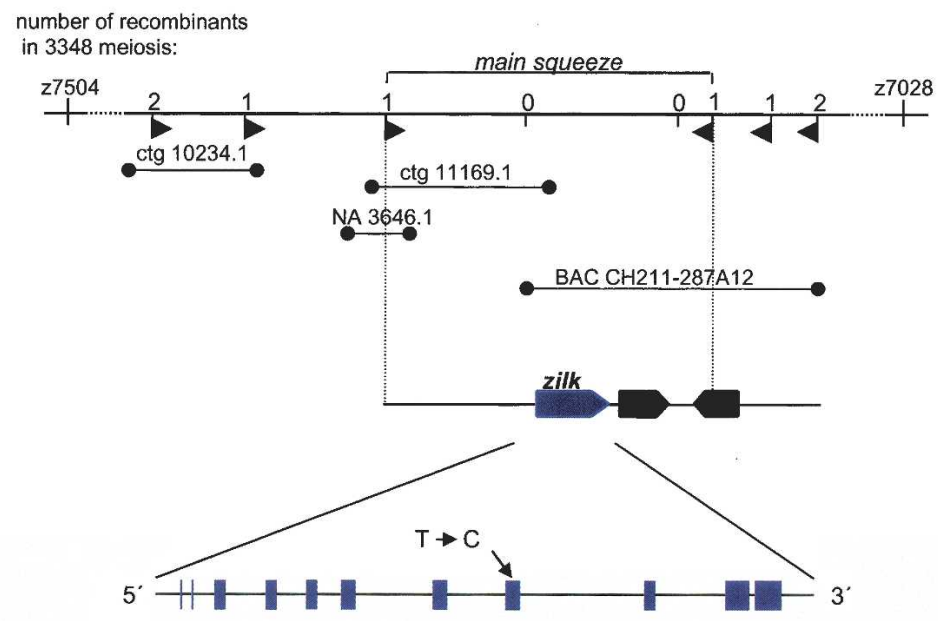

B

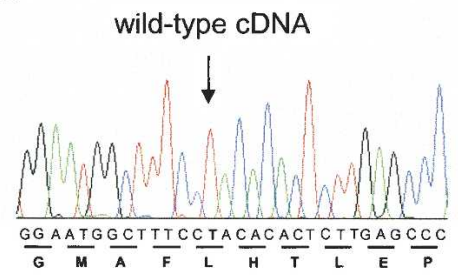

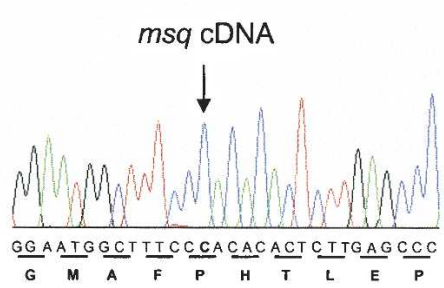

C

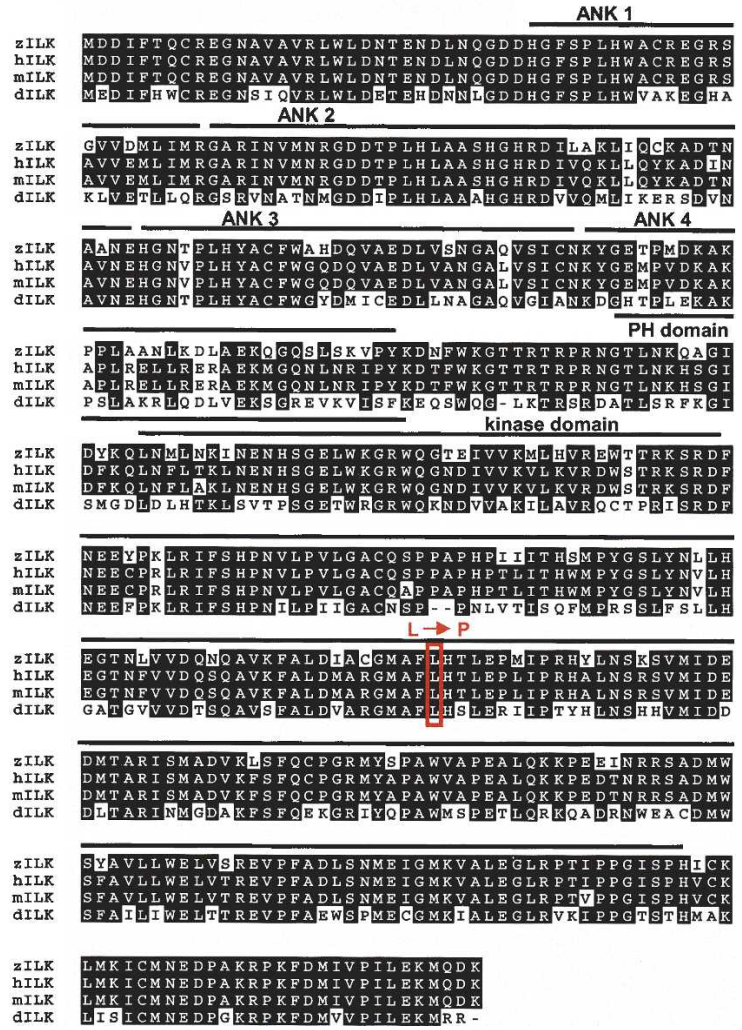

Figure 2. $m s q$ encodes zebrafish ILK and is highly conserved between different species. $(A)$ Integrated genetic and physical map of the zebrafish $m s q$ region. The $m s q$ mutation interval is flanked by the microsatellite markers z7504 and z7028. A bacterial artificial chromosome (BAC) clone CH211-287A12 and sequence contigs ctg1169.1 and NA 3646.1 (Sanger assembly Zv2) cover the msq interval and encode three ORFs, highly homologous to human Sphingomyelinase, ILK, and an unknown protein (Riken 2210415M20). The genomic structure of zebrafish ilk (zilk) is displayed at the bottom of the figure. The msq missense mutation ( T $\rightarrow \mathrm{C}$ ) in the eighth exon of zilk is indicated. $(B)$ The $m s q$ missense mutation $(\mathrm{T} \rightarrow \mathrm{C})$ at cDNA position 923 translates into an amino acid exchange from leucine $(\mathrm{L})$ to proline $(\mathrm{P})(\mathrm{CTA} \rightarrow \mathrm{CCA})$. The mutated base is marked by an arrow. $(C)$ Amino acid sequence alignment of zebrafish (zILK), human (hILK), mouse (mILK), and D. melanogaster (dILK) ILK demonstrates high amino acid identity cross-species. Black boxes indicate amino acid identity. Functional domains, such as ankyrin domains (ANK), a PH domain, and the C-terminal ILK kinase domain are indicated with bars above the alignment. The $m s q$ mutation ILK ${ }^{\mathrm{L} 308 \mathrm{P}}$ resides within the kinase domain of ILK.

expression of the stretch-responsive gene zanf is severely down-regulated (Fig. 3D-G), and fractional shortening of the ventricular chamber consecutively decreases to $0.63 \pm 1.77 \%$ at $72 \mathrm{hpf}$ (Fig. $3 \mathrm{H}$; Supplementary Movie 2). Isolation of RNA from MO2-zilk-injected embryos confirmed the predicted effect on zilk mRNA splicing, namely, either skipping of exon 4 (125-base-pair [bp] product) or integration of intron 4 (370-bp product), both leading to premature termination of translation (Fig. $3 \mathrm{H}$, inset). Wild-type zilk cDNA (224-bp product) was not detected in the injected embryos even $72 \mathrm{~h}$ after injection. These findings implicate that loss of cardiac ventricular contractility and reduced expression of the stretch-responsive genes anf and vegf in $m s q$ mutants are due to loss of ILK function.

\section{ilk $m R N A$ restores ventricular contractility in $\mathrm{msq}$ mutant embryos}

Our morpholino knockdown experiments imply that the $m s q$ mutation interferes with an essential function of
zILK in ventricular cardiomyocytes. We therefore evaluated whether ventricular contractility in $m s q$ mutant embryos can be restored by ectopic expression of wildtype zilk mRNA. After injection of 300 pg of wild-type zilk mRNA $\left(\right.$ zilk $\left.^{\mathrm{wt}}\right), 83 \%$ of the injected msq mutant embryos (24 out of 29) displayed normal ventricular function by $72 \mathrm{hpf}$. In contrast, injection of $m s q$ mutant zilk mRNA (zilk ${ }^{\mathrm{L} 308 \mathrm{P}}$ ) at various concentrations (300$500 \mathrm{pg}$ ) did not rescue the contractile dysfunction in $\mathrm{msq}$ mutant embryos (0 out of 50) (Fig. 3I).

As described above, zILK and hILK show 86\% amino acid identity (Fig. 2C). To test if the functional role of ILK in maintaining cardiac ventricular contractility is conserved between zebrafish and human, we injected human ilk mRNA (hilk ${ }^{\mathrm{wt}}$ ) into one-cellstage embryos derived from intercrossing $m s q$ heterozygous +/- zebrafish. When injecting 500 pg of fulllength hilk ${ }^{\mathrm{wt}}, 43 \%$ of $\mathrm{msq}$ mutant embryos (18 out of 42) displayed normal ventricular contractility at $72 \mathrm{hpf}$ (Fig. 3I). 


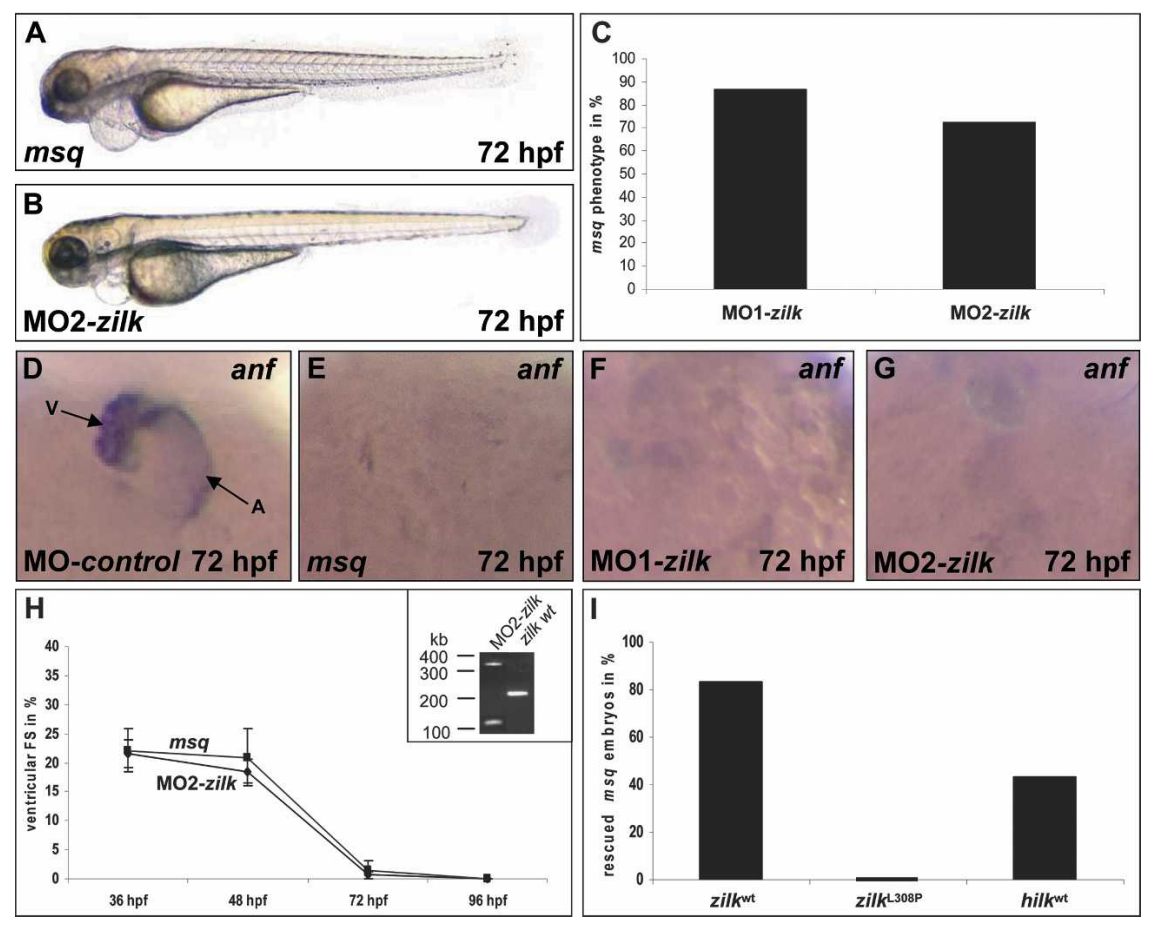
(integration of intron 4) and $125 \mathrm{bp}$ (skipping of exon 4), predicted to lead to premature termination of translation of zilk (I) Ectopic expression of wild-type ilk RNA from either zebrafish (zilk $\left.{ }^{\mathrm{wt}}\right)$ or human (hilk $\left.{ }^{\mathrm{wt}}\right)$ can rescue the heart phenotype of a significant proportion of $m s q$ mutant embryos, whereas injection of $m s q$ mutant RNA (zilk $\left.{ }^{\mathrm{L} 308 \mathrm{P}}\right)$ has no effect.

These data confirm that the $\operatorname{zILK}^{\mathrm{L} 308 \mathrm{P}}$ mutation is, indeed, responsible for the $m s q$ cardiac phenotype, and imply that the function of ILK in maintaining cardiac contractility is conserved between zebrafish and human.

\section{zILK specifically localizes to costameres and Z-discs of heart and skeletal muscle}

In other species, ilk is widely expressed both during embryonic development and in the adult, with highest expression observed in heart and skeletal muscle, blood vessels, and the pancreas (Hannigan et al. 1996; Zervas et al. 2001; Mackinnon et al. 2002). Similarly, by 72 hpf, zilk RNA expression is pronounced in the heart and skeletal muscle of zebrafish embryos. zilk mRNA expression levels do not differ between wild-type and msq mutant embryos (data not shown).

To further determine the localization of zILK protein in the heart and within cardiomyocytes, we performed immunostaining with a monoclonal antibody raised against full-length human ILK (Li et al. 1999). As shown in Figure 4A, ILK expression can be detected both in the endocardial and myocardial layer of the zebrafish embryonic heart. Within cardiomyocytes, zILK shows a striated distribution and colocalizes with the sarcomeric $\mathrm{Z}$ disc protein $\alpha$-Actinin (Fig. 4B,C). A similar subcellular localization can be observed in skeletal muscle cells (Fig. 4D), where zILK also localizes to the sarcolemma, enriched at those areas of the cell membrane where Z-bands anchor. The same pattern is observed in adult
Figure 3. Antisense oligonucleotidemediated knockdown of zilk phenocopies the $m s q$ mutant heart phenotype, whereas ectopic expression of wild-type ILK suppresses cardiac dysfunction in $\mathrm{msq}$ mutants. (A-H) Inhibition of zilk function by morpholino-modified antisense oligonucleotide injection phenocopies the $m s q$ mutant phenotype. MO2-zilk injected embryos $(B)$ are indistinguishable from $m s q$ mutant embryos $(A)$ and display severe impairment of ventricular contractility $(H)$. (C) Eighty-seven percent of MO1-zilk-injected, and $72.1 \%$ of MO2-zilk-injected wild-type embryos display the $m s q$ mutant phenotype at $72 \mathrm{hpf}$. $(D-G)$ Similar to the situation in $m s q$ mutant hearts $(E)$, injection of either MO1-zilk (F) or MO2-zilk $(G)$ leads to reduced zanf RNA levels in the heart. $(D)$ In contrast, injection of MOcontrol has no effect on zanf expression. Atrium (A) and ventricle (V) are indicated. $(H)$ Ventricular fractional shortening (FS) of MO2-zilk-injected and msq mutant embryos. The effect of MO2-zilk on mRNA splicing is shown in the inset. Injection of MO2-zilk results in abnormal splice prod-

zebrafish (Fig. 4E) and rat cardiomyocytes (Fig. 4F). In addition, immuno-gold staining and consecutive transmission electron microscopy confirms that some ILK protein localizes directly to the sarcomeric Z-disc of cardiomyocytes (Fig. 4G). Taken together, these findings demonstrate that in cardiomyocytes and skeletal muscle cells, ILK is concentrated to regions on the sarcolemma, where Z-bands attach, the so-called costameres.

To further evaluate if the msq mutation ILK $^{\mathrm{L} 308 \mathrm{P}}$ interferes with zILK stability and its subcellular localization to costameres and Z-discs in cardiomyocytes and skeletal muscle cells, we analyzed zILK expression in $m s q$ mutant zebrafish embryos by immunostaining. As shown in Figure 4, H and I, the ILK antibody readily recognizes mutant $\mathrm{ILK}^{\mathrm{L} 308 \mathrm{P}}$, and there is no difference in the expression level and intracellular localization of zILK in comparison to wild-type zebrafish embryos (Fig. $4 \mathrm{~A}, \mathrm{D})$, indicating that $m s q$ mutant $\mathrm{ILK}^{\mathrm{L} 308 \mathrm{P}}$ protein is stable and localizes correctly to costameric units of heart and skeletal muscle cells.

The msq ILK ${ }^{L 308 P}$ mutation leads to reduced ILK kinase activity

The ms $q$ mutation $\mathrm{ILK}^{\mathrm{L} 308 \mathrm{P}}$ resides within the highly conserved serine/threonine kinase domain of ILK (Delcommenne et al. 1998; Yamaji et al. 2001). Specific residues within the kinase domain, such as the arginine residue at position 211, are known to be essential for ILK kinase activity (Persad et al. 2001a). 
Bendig et al.

Figure 4. ILK localizes to the sarcolemma and sarcomeric Z-discs of cardiomyocytes. (A) ILK is expressed in the endocardial (en) and myocardial (my) layer of the zebrafish heart. Cross-section through the cardiac ventricle of a wild-type zebrafish embryo at 72 hpf. $(B, C)$ Coimmunostaining with an antibody directed against the sarcomeric Zdisc protein $\alpha$-Actinin reveals colocalization of ILK and $\alpha$-Actinin in zebrafish cardiomyocytes. $(C)$ Merge of the anti-ILK and anti- $\alpha$-Actinin stain. (D) As already observed in cardiomyocytes $(C)$, ILK and $\alpha$-Actinin also colocalize at sarcomeric Z-discs of zebrafish skeletal muscle cells. In addition, as indicated by arrowheads, sarcolemmal localization of ILK can be observed. (E$G)$ In the adult zebrafish $(E)$ and $\operatorname{rat}(F, G)$ heart, ILK and $\alpha$-Actinin also colocalize at sarcomeric Z-discs. (G) Immuno-gold staining and transmission electron microscopy of rat heart sections confirms localization of ILK at sarcomeric Z-discs. $(H, I)$ msq mutant ILK $^{\mathrm{L} 308 \mathrm{P}}$ is expressed at normal levels in $m s q$ mutant zebrafish hearts $(H)$ and skeletal muscle $(I)$, and shows sarcolemmal staining (indicated by arrowheads) and colocalization with $\alpha$-Actinin.
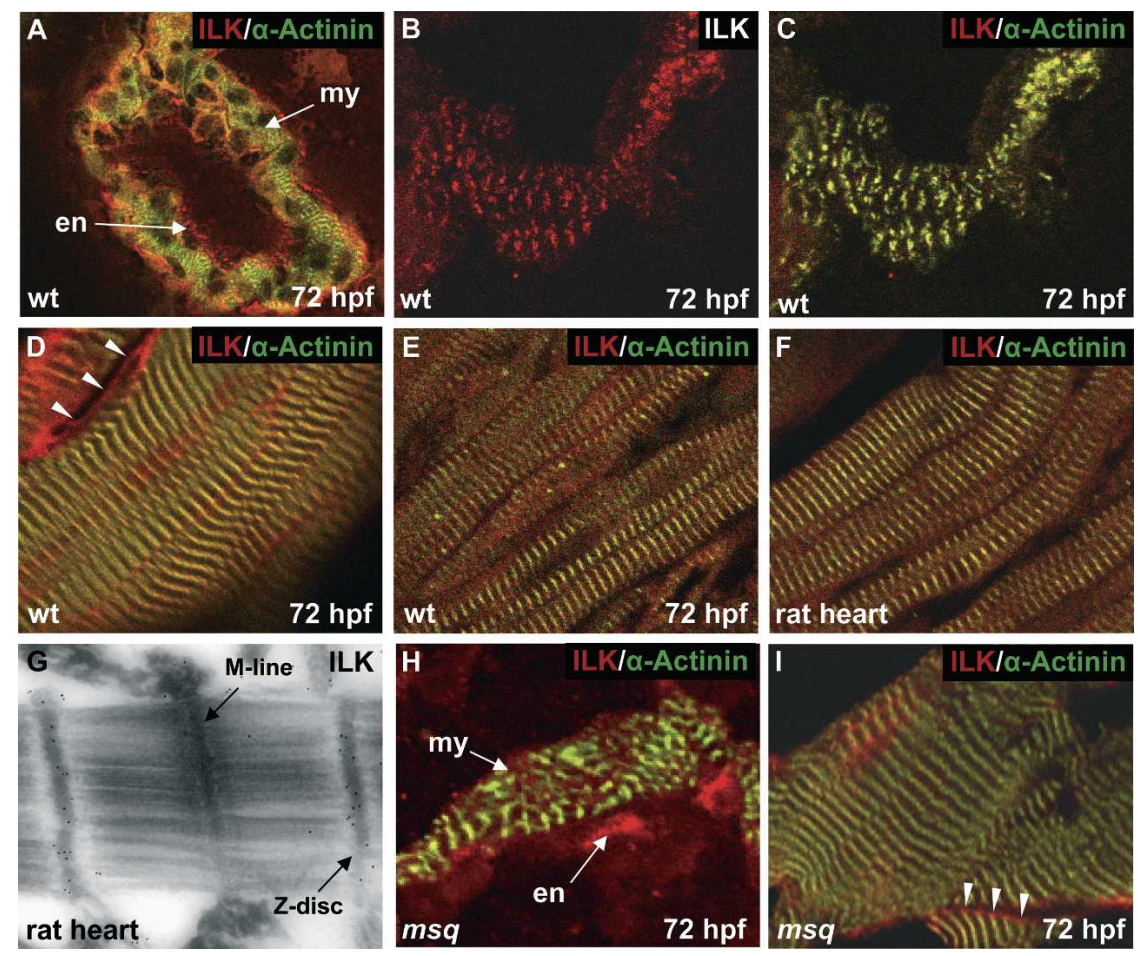

Therefore, to examine if the $m s q$ mutation impairs ILK kinase activity and thereby reduces cardiac contractility, we assayed the kinase activity of $m s q$ mutant $\left(\right.$ ILKK $\left.^{\mathrm{L} 308 \mathrm{P}}\right)$ and wild-type $\left(\mathrm{zILK}^{\mathrm{wt}}\right)$ ILK in vitro. As shown in Figure 5A, phosphorylation of MBP by msq mutant zILK $^{\mathrm{L} 308 \mathrm{P}}$ was reduced by $~ 58 \%$ in comparison to phosphorylation by wild-type zILK ${ }^{\mathrm{wt}}$. Similarly, autophosphorylation of $z \mathrm{ILK}^{\mathrm{L} 308 \mathrm{P}}$ was reduced by $\sim 50 \%$ in comparison to wild-type zILK (Fig. 5A). To further evaluate whether reduction of IILK $^{\mathrm{L} 308 \mathrm{P}}$ kinase activity accounts for the msq mutant heart phenotype in vivo, we evaluated the ability of kinase-deficient human ILK (hILK ${ }^{\text {R211A) }}$ (Persad et al. 2001a) to reconstitute cardiac contractility in msq mutants. Strikingly, in contrast to hilk ${ }^{w t}$ mRNA, injection of even high amounts (300-800 pg) of kinase-deficient hilk ${ }^{R 211 A}$ mRNA was not sufficient to suppress the cardiac phenotype in homozygous mutant msq embryos (0 out of 71 ) (Fig. 5B). In summary, our findings indicate that reduced kinase activity of $m s q$ mutant zILK $^{\mathrm{L} 308 \mathrm{P}}$ might account for loss of cardiac contractility in $m s q$ mutant embryos.

\section{PKB and VEGF act downstream of ILK in controlling vertebrate heart contractility}

ILK directly phosphorylates PKB at Ser 473, thereby leading to full activation of PKB (Persad et al. 2001a). Furthermore, ILK controls transcription of vegf via PKB phosphorylation (Tan et al. 2004). We recently demonstrated that VEGF controls calcium cycling and contractility of the zebrafish embryonic heart (Rottbauer et al. 2005). Therefore, we speculated that reduced kinase ac- tivity of msq mutant ILK might disturb ILK-PKB-VEGF signaling in cardiomyocytes, leading to the msq mutant heart phenotype.

To further elucidate whether PKB acts downstream of ILK to control cardiac contractility in $m s q$ mutant hearts, we injected constitutively active, myristoylated PKB (myrpkb) mRNA, which was recently shown to be functional in zebrafish (Chan et al. 2002) into msq mutant embryos. After injection of $500 \mathrm{pg}$ of myrpkb mRNA, $53 \%$ of the injected msq mutant embryos 36 out of 68) displayed normal ventricular contractility by 72 hpf (Fig. 5B), whereas injection of a kinase-dead version of myristoylated PKB (inactpkb) mRNA at various concentrations (500-800 pg) had no effect on the contractile dysfunction in $m s q$ mutant embryos $(0$ out of 68) (Fig. 5B), indicating that reduced PKB activity downstream of ILK might account for heart failure of msq mutants. Interestingly, in whole-embryo lysates, phosphorylation of PKB at Ser 473 did not significantly differ between wild-type and $m s q$ mutants, indicating that besides ILK other kinases might contribute to full activation of PKB, at least in tissues other than the heart.

In our initial screen, VEGF expression was found to be sixfold down-regulated in msq mutant hearts. To test whether reduced VEGF expression is directly involved in loss of cardiac contractility in msq mutants, we injected zvegf mRNA into msq mutant embryos and evaluated their heart function. After injection of $250 \mathrm{pg}$ of zvegf $f_{121}$ mRNA, $10 \%$ of the injected msq mutant embryos 3 out of 30) displayed completely restored ventricular function by 84 hpf (Fig. 5B). Additional 17\% (5 out of 30) of injected $m s q$ mutant embryos showed weak ventricular 
A

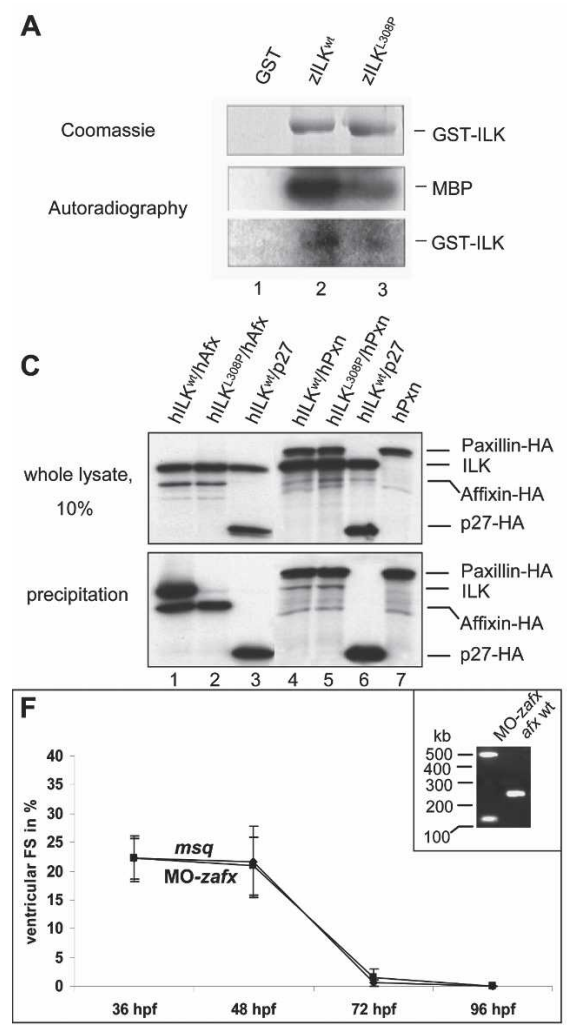

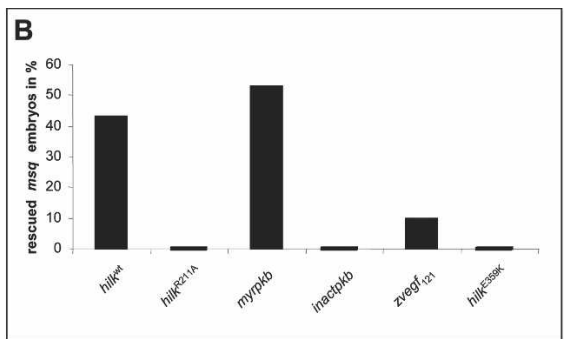

D

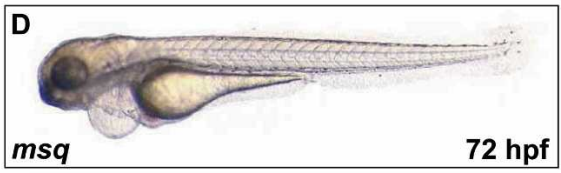

E
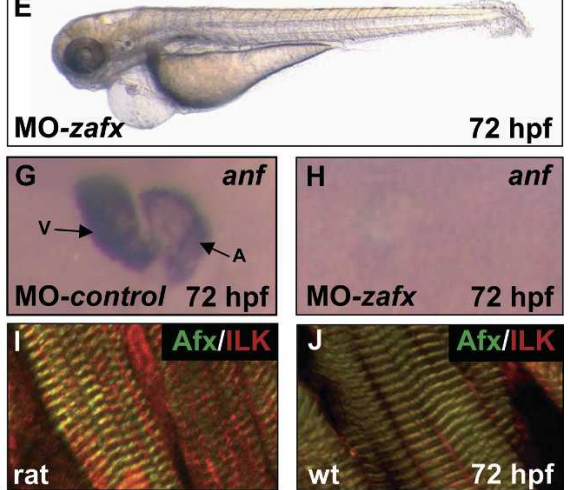

Figure 5. $m s q$ mutant $\mathrm{ILK}^{\mathrm{L} 308 \mathrm{P}}$ disrupts ILK kinase activity and its binding to $\beta$-parvin (Affixin). (A) In comparison to zILK $^{\mathrm{wt}}$, the $m s q$ mutation $\mathrm{zILK}^{\mathrm{L} 308 \mathrm{P}}$ leads to potent reduction of phosphorylation of the substrate MBP (middle part), as well as of ILK autophosphorylation (lower part). (Upper part) Identical amounts of purified recombinant $z \mathrm{ILK}^{\mathrm{wt}}$ (lane 2) and $\mathrm{ILK}^{\mathrm{L} 308 \mathrm{P}}$ (lane 3) were used. Lane 1 shows incubation of MBP with GST as a control. (B) Rescue of the msq mutant heart phenotype by mRNA injection of various constructs. Kinase-deficient hilk (hilk ${ }^{\mathrm{R} 211 \mathrm{~A}}$ ), as well as hilk deficient in $\beta$-parvin binding (hilk ${ }^{\mathrm{E} 359 \mathrm{~K}}$ ) fail to rescue the msq mutant phenotype, whereas wild-type hilk ${ }^{\mathrm{wt}}$ is able to rescue the $m s q$ phenotype. Injection of either $z v e g f_{121}$ mRNA, or myristoylated human PKB (myr$p k b)$ mRNA suppresses the msq mutant phenotype. Injection of kinase inactive hPKB (inactpkb) mRNA has no effect. (C, lower panel) In vitro coimmunoprecipitation with human $\beta$-parvin, Paxillin, and ILK. HA-tagged $h \beta$-parvin (hAfx) interacts with wild-type hILK ${ }^{\text {wt }}$ (lane 1), but not with mutant hILK ${ }^{\mathrm{L} 308 \mathrm{P}}$ (lane 2). In contrast, HAtagged hPaxillin ( $\mathrm{hPxn}$ ) precipitates with both hILK ${ }^{\text {wt }}$ (lane 4) and hILK ${ }^{\mathrm{L} 308 \mathrm{P}}$ (lane 5). (Lanes 3,6) As a control, HA-tagged $\mathrm{hp} 27^{\mathrm{Kip} 1}$ is used. Lane 7 indicates precipi-tation of HA-tagged hPaxillin to exclude degradation products of hPaxillin migrating at the size of hILK. The upper panel shows 10\% input of the radiolabeled, cotranslated proteins. $(D-H)$ Antisense oligonucleotide-mediated knockdown of zebrafish $\beta$-parvin (affixin) phenocopies the msq mutant heart phenotype. MO-zafX injected embryos $(E)$ are indistinguishable from msq mutant embryos $(D)$ and display severe impairment of ventricular contractility. $(F)$ Similar to msq mutant embryos, fractional shortening (FS) of the ventricular chamber decreases significantly in MO-zafx-injected embryos. The effect of MO-zafX on mRNA splicing is shown in the inset. Injection of MO-zafx results in abnormal splice products of 500 bp (integration of intron 5) and $125 \mathrm{bp}$ (skipping of exon 5), both predicted to lead to premature termination of translation of zilk. (G,H) In contrast to wild-type hearts $(G)$, zanf RNA cannot be detected by RNA antisense in situ hybridization in hearts from MO-zafx injected embryos at $72 \mathrm{hpf}(H)$. Atrium $(\mathrm{A})$ and ventricle $(\mathrm{V})$ are indicated. $(I, J) \beta$-Parvin $(\mathrm{Afx})$ and ILK colocalize at sarcomeric Z-discs of zebrafish $(J)$ and rat hearts $(I)$.

contractions, resembling partial rescue of $m s q$ mutant heart failure. These findings indicate that VEGF can restore ventricular contractility in $m s q$ mutant embryos and might act downstream of ILK and PKB in the cardiac stretch sensory pathway.

msq mutation ILK $K^{L 308 P}$ disrupts binding of ILK to $\beta$-parvin (Affixin)

The msq mutation resides in the C terminus of ILK, where, in addition to the kinase domain, several proteinbinding domains are located, including those for Paxillin and $\beta$-parvin, two proteins known to be expressed in the heart (Yamaji et al. 2001). Therefore, in a coimmunoprecipitation assay with $\left[{ }^{35} \mathrm{~S}\right]$-labeled cotranslated proteins, we evaluated whether the msq mutation ILK ${ }^{\mathrm{L} 308 \mathrm{P}}$ disrupts ILK binding to either Paxillin and/or $\beta$-parvin. As shown in Figure 5C, both wild-type ILK (hILK) (lane 4) and mutant hILK ${ }^{\mathrm{L} 308 \mathrm{P}}$ (lane 5) bind hPaxillin. In contrast, whereas wild-type hILK is able to bind $\mathrm{h} \beta$-parvin (Fig. 5C, lane 1), hILK ${ }^{\mathrm{L} 308 \mathrm{P}}$ (Fig. 5C, lane 2) is not. The same result was obtained when $\left[{ }^{35} \mathrm{~S}\right]$-labeled ILK ${ }^{\mathrm{wt} / \mathrm{L} 308 \mathrm{P}}$ was incubated with purified recombinant GST-Paxillin or GST- $\beta$-parvin, respectively (data not shown). To further determine if disruption of ILK- $\beta$-parvin binding accounts for the msq mutant heart phenotype, we injected another mutant form of ILK (hilk ${ }^{\mathrm{E} 359 \mathrm{~K}}$ ) with greatly reduced $\beta$-parvin binding (Yamaji et al. 2001) into offspring derived from intercrossing $m s q$ heterozygous $+/-$ zebrafish. However, in contrast to hilk ${ }^{\mathrm{wt}}$, hilk ${ }^{\mathrm{E} 359 \mathrm{~K}} \mathrm{RNA}$ injection at various concentrations (300-500 pg) did not reconstitute ventricular contractility in $\mathrm{msq}$ mutant embryos (0 out of 44 ) (Fig. 5B), indicating that binding of ILK to $\beta$-parvin is essential for maintenance of cardiac ventricular contractility.

\section{Antisense oligonucleotide mediated knockdown of zebrafish $\beta$-parvin (Affixin) phenocopies the msq mutant heart phenotype}

We demonstrated above that the ms $q$ mutation ILK $^{\mathrm{L} 308 \mathrm{P}}$ specifically inhibits ILK- $\beta$-parvin binding without affecting the interaction with Paxillin, and that the physical interaction of ILK and $\beta$-parvin is essential to main- 
tain cardiac contractility. The in vivo function of $\beta$-parvin has not yet been evaluated in vertebrates.

As shown in Figure 5, I and J, $\beta$-parvin and ILK colocalize at sarcomeric Z-discs of rat heart and zebrafish skeletal muscle cells. In msq mutants, $\beta$-parvin is also localized at costameres of cardiomyocytes and skeletal muscle cells, indicating that ILK- $\beta$-parvin binding is not essential for $\beta$-parvin localization within muscle cells (data not shown). To gain further insight into the role of $\beta$-parvin in vivo, we designed a morpholino-modified antisense oligonucleotide directed against the splice donor site of exon 5 (MO-zafx) of $z \beta$-parvin (affixin) (GenBank accession no. DQ499602) and injected it into wild-type zebrafish embryos at the one-cell stage. When injecting $2.7 \mathrm{ng}$ of MO-zafx into zebrafish wild-type embryos, $>60 \%$ of the injected embryos (51 out of 86 ) revealed a phenotype identical to the one observed in $m s q$ mutant embryos (Fig. 5D-H; Supplementary Movie 3). In the MO-zafX-injected embryos, fractional shortening of the ventricle decreased down to $0.57 \pm 1.8 \%$ by 72 hpf (Fig. $5 F)$. Similar to $m s q$ mutant hearts, the expression of the stretch-responsive factor anf was also found to be severely down-regulated in MO-zafx-injected embryos, in comparison to MO-control-injected embryos (Fig. 5G,H). Isolation of RNA from MO-zafx-injected embryos confirmed the predicted effect on mRNA splicing, namely, either skipping of exon 5 (129-bp product) or integration of intron 5 (500-bp product), both leading to premature termination of translation. Wild-type zaf $x$ cDNA (266-bp product) could not be detected in the injected embryos even at $72 \mathrm{hpf}$ (Fig. 5F, inset). In contrast to the knockdown of $\beta$-parvin, knockdown of Paxillin via injection of morpholino-modified antisense oligonucleotides did not phenocopy the msq mutant phenotype (data not shown), underlining the specific role of $\beta$-parvin in the regulation of heart contractility.

siRNA-mediated knockdown of parvins was recently found to result in concomitant decrease in ILK levels, most likely due to protein degradation (Fukuda et al. 2003). Therefore, the cardiac phenotype of $\beta$-parvin-depleted zebrafish embryos might be due to reduced ILK protein levels. Indeed, we also observed severely reduced ILK protein levels in $\beta$-parvin-deficient zebrafish embryos, demonstrating that $\beta$-parvin is essential in vivo to maintain ILK stability and hence cardiac contractility.

\section{Discussion}

The sensing of mechanical stimuli (mechano-sensing) and the transduction of these signals into cellular responses (mechano-transduction) are hallmarks of the vertebrate heart and vital to its function. However, the integrative components that allow cardiac myocytes to sense mechanical strain/stress and adjust their force of contraction are only poorly defined. Here we show that ILK is a novel component of such a cardiac stretch sensor, fulfilling both a structural role as a mechanical integration site that links membrane-bound $\beta$-Integrins via $\beta$-parvin (Affixin) and $\alpha$-Actinin to the sarcomeric
Z-disc, and a functional role in the regulation of cardiomyocyte contractility via PKB/VEGF signaling.

We describe here a mutation in zebrafish ilk, main squeeze, which impairs cardiac contractility and leads to reduced expression of the stretch-responsive factors ANF and VEGF. ILK specifically localizes to costameres and sarcomeric Z-discs, the mechanical integration sites of cardiomyocytes. ms $q$ mutant ILK ${ }^{\mathrm{L} 308 \mathrm{P}}$ displays reduced ILK kinase activity. ILK was recently shown to regulate vegf transcription by PKB activation during tumor angiogenesis (Tan et al. 2004). Similarly, we demonstrate here that both PKB and VEGF act downstream from ILK in the vertebrate heart, since the $m s q$ heart failure phenotype can be rescued by ectopic expression of constitutively active PKB or VEGF. Furthermore, the msq mutation specifically disrupts binding of ILK to the Z-disc protein $\beta$-parvin, and accordingly cardiac contractility cannot be restored by ectopic expression of $\beta$-parvin-binding-deficient $\mathrm{ILK}^{\mathrm{E} 359 \mathrm{~K}}$. Antisense oligonucleotide-mediated knockdown of zebrafish $\beta$-parvin leads to a cardiac phenotype identical to $m s q$. Injected embryos develop heart failure and show severely reduced cardiac expression of the stretch-responsive factor ANF. Therefore, we postulate that the vertebrate heart uses the Integrin-ILK- $\beta$ parvin network to sense mechanical stretch and to respond with increased expression of ANF and VEGF, the latter of which is known to augment cardiac force by increasing the heart's calcium transients (Rottbauer et al. 2005).

Molecular pathways controlling cardiac function in general and the role of ILK in particular are difficult to dissect genetically in placental animals because disturbance of the cardiovascular system leads to early embryonic death. Nullizygous ilk mice die shortly after implantation (Sakai et al. 2003), and mice with endothelial cell-specific deletion of ILK confer placental insufficiency and die at embryonic day 11.5 (E11.5) (Friedrich et al. 2004). In contrast to mammals, intact cardiovascular function is not essential for the early development of the zebrafish embryo, because it obtains adequate oxygen by diffusion from its environment (Burggren and Pinder 1991; Stainier and Fishman 1994). Zebrafish msq mutant embryos survive for days to late larval stages, permitting here, for the first time, a detailed analysis of the role of ILK in vertebrate cardiac function.

Using gene knockdown and knockout strategies in mice, proteins of the costameric multiprotein complex as well as of the sarcomeric Z-disc were recently proposed to be involved in mechano-transduction and regulation of cardiac contractility (Samarel 2005). For instance, ventricular cardiomyocyte-specific disruption of $\beta$-Integrin function in mice results in perinatal lethality and, in milder cases, in abnormal cardiac performance with reduced basal contractility and relaxation of the heart (Keller et al. 2001). Similarly, mice deficient in Melusin, a $\beta 1$-Integrin-binding protein, develop heart dilatation and contractile dysfunction when subjected to pressure overload by aortic banding (Brancaccio et al. 2003), while overexpression of Melusin protects from dilated cardiomyopathy (De Acetis et al. 2005). Mice defi- 
cient in the Z-disc protein MLP also develop progressive dilated cardiomyopathy (Hongo et al. 2000). Interestingly, MLP-deficient heart muscle cells fail to respond to passive stretch by increased contractile force or a compensatory gene program (i.e., anf expression) that aims to augment contractile force. Similar to these mice models with disturbed cardiac stretch sensor function, ILK-deficient $m s q$ mutant zebrafish embryos display reduced expression of the stretch-responsive factors anf and vegf in the heart, and consequently develop heart failure. ILK is known to bind to cytosolic $\beta$-Integrin subunits and, as shown here, to specifically localize to costameres and Z-discs of cardiomyocytes. This role, connecting transmembrane receptors to sarcomeric structures, makes ILK a likely candidate responsible for Integrin-mediated mechano-sensing/mechano-transduction in the heart. In this context, it is interesting to note that ILK contains four ankyrin domains at its $\mathrm{N}$ terminus. Ankyrin repeat domains are found in many proteins that interact with membrane transporters, receptors, and cell adhesion molecules, and therefore supposedly have a role in sensing and responding to mechanical strain. Ankyrin repeat domains recently were found to exhibit tertiary-structure-based elasticity and to behave as nanosprings (Lee et al. 2006). Thus, ILK might also provide with its ankyrin repeat domains the structural prerequisites for acting as an elastic mechano-sensor in cardiomyocytes. There is also evidence that ILK itself is involved in the sensing of mechanical signals in non-muscle cells. Nho and colleagues have recently shown that matrix-derived mechanical forces sensed by $\beta 1$-Integrin are capable of modulating ILK activity downstream of PI3K, which in turn regulates fibroblast viability via PKB-dependent mechanisms (Nho et al. 2005).

In some circumstances, ILK has been shown to be important for cell proliferation, differentiation, or cell survival (Guo and Wu 2002; Miller et al. 2003; Bock-Marquette et al. 2004). Flies and worms deficient in ILK are viable but manifest muscle detachment (Zervas et al. 2001; Mackinnon et al. 2002), and endothelial cell-specific deletion of ILK in mice confers placental insufficiency and leads to increased apoptosis (Friedrich et al. 2004). However, in msq mutants, proliferation, differentiation, and survival are normal in both cardiomyocytes and skeletal muscle cells, suggesting that its role is more functional than structural in the vertebrate heart.

The msq mutant heart phenotype cannot be suppressed by ectopic expression of kinase-deficient ILK $\left(\mathrm{ILK}^{\mathrm{R} 211 \mathrm{~A}}\right)$, pointing toward an essential role of ILK kinase activity in the pathogenesis of the $m s q$ heart failure phenotype. The msq mutation resides within the C-terminal kinase domain of ILK, and ILK kinase activity of $m s q$ mutant ILK ${ }^{\mathrm{L} 308 \mathrm{P}}$ is significantly down-regulated. Basal ILK kinase activity is usually low, but is stimulated in a phosphatidylinositol (PI) 3 kinase-dependent manner (Dedhar 2000). PI3,4,5-triphosphate binding as well as (auto) phosphorylation appear to be crucial for ILK activation, since a mutation in the $\mathrm{PH}$ domain (Arg211Ala) renders the ILK kinase inactive (Persad et al. 2001a). In contrast, the skeletal muscle phenotype of
ILK-deficient flies and worms can be rescued by kinasedead ILK, indicating that kinase activity of ILK is not essential in invertebrates and that the main function of ILK may be a structural adaptor between the plasma membrane and the cytoskeleton at sites of Integrin-mediated cell adhesion (Zervas et al. 2001; Mackinnon et al. 2002).

Many downstream proteins have been identified as in vivo targets of ILK kinase activity, including PKB. Several studies indicate that the kinase activity of ILK is directly responsible for the phosphorylation of Ser 473 and thereby full activation of PKB (Delcommenne et al. 1998; Persad et al. 2000, 2001b; Zhang et al. 2002; Attwell et al. 2003). However, the mechanism by which ILK promotes PKB phosphorylation is controversial, as other studies suggest that ILK may function in the role of an adaptor protein rather than a kinase in regulating PKB activity (Legate et al. 2006). We show here that ectopic expression of constitutively active PKB reconstitutes cardiac function in $m s q$ mutant embryos, implicating PKB as a downstream effector of ILK in the zebrafish heart.

We identified the msq zebrafish mutant by analyzing cardiac expression of the stretch-responsive factors anf and vegf, both of which we found to be severely downregulated in msq mutant hearts. Interestingly, ILK-PKB signaling is a known regulator of vegf transcription during tumor angiogenesis (Tan et al. 2004). Therefore, one might postulate that VEGF expression in $m s q$ mutant hearts is reduced due to disturbed ILK-PKB signaling. Accordingly, as demonstrated here, ectopic expression of VEGF can directly reconstitute cardiac contractility in ms $q$ mutant embryos. Our findings suggest that the $m s q$ mutation in ILK leads to decreased kinase activity, resulting in reduced phosphorylation of PKB and, consequently, in reduced transcription of vegf, which is known to be essential for heart contractility by modulating calcium cycling of cardiomyocytes (Rottbauer et al. 2005). anf transcription also depends on PKB activation and subsequent phosphorylation/inhibition of GSK$3 \beta$ (Morisco et al. 2000), both known downstream effectors of ILK. PKB has recently been shown to be activated in response to mechanical forces in a variety of different cell types, including endothelial cells (Dimmeler et al. 1998), vascular smooth muscle cells (Sedding et al. 2005), and heart muscle cells (Petroff et al. 2001).

ILK is known to interact with $\beta$-parvin (Affixin), $\alpha$-parvin (CH-ILKBP), Paxillin, and others via its $\mathrm{C}$ terminus (Wu and Dedhar 2001), where the kinase domain and the $m s q$ mutation reside. The contractility defects at least in part reflect the interference with $\beta$-parvin binding. The ILK ${ }^{\mathrm{L} 308 \mathrm{P}}$ mutation specifically disrupts binding to $\beta$-parvin, while interaction with Paxillin is not disturbed. Another ILK mutant, ILK ${ }^{\mathrm{E} 359 \mathrm{~K}}$, with greatly reduced binding to $\beta$-parvin (Yamaji et al. 2001) also cannot rescue the msq mutant phenotype. However, since $\mathrm{ILK}^{\mathrm{E} 359 \mathrm{~K}}$ was also found to be reduced in its kinase activity (Novak et al. 1998), failure to rescue the msq mutant phenotype might be due to both kinase and $\beta$-parvin-binding deficiency of this mutant. Further- 
more, knockdown of $\beta$-parvin leads to the same selective cardiac phenotype as observed in msq mutant embryos, most likely by interference with ILK stability.

In vertebrates, the heart and vasculature have great ability to match function to hemodynamic needs. Some of this is due to homeostatic mechanisms extrinsic to the heart, such as sympathetic nerve activation and adrenal medullary release of catecholamines. In addition, there is a powerful system intrinsic to the heart that matches the input to the output of the heart. This socalled Frank-Starling relationship, first described in 1918, is manifest even in an isolated heart (Starling 1918). The work reported here suggests for the first time that ILK, and associated proteins such as $\beta$-parvin, are essential components of a mechanical stretch sensor in the heart, and therefore might play a crucial role in the intrinsic adaptation of the heart to continually changing demands.

\section{Materials and methods}

Histology, transmission electron microscopy, immunostaining, and RNA antisense in situ hybridization

For histology, embryos were fixed in $4 \%$ paraformaldehyde and embedded in JB-4 (Polysciences, Inc.). Five-micrometer sections were cut, dried, and stained with hematoxylin/eosin. Electron micrographs were obtained essentially as described (Rottbauer et al. 2001). Whole-mount RNA in situ hybridization was carried out essentially as described (Jowett and Lettice 1994) using a digoxigenin-labeled full-length zilk antisense probe, as well as a digoxigenin-labeled antisense probe for zanf.

Immunostaining was performed on 7- $\mu \mathrm{m}$ cryosections, using the monoclonal anti-ILK IgG2b antibody (Upstate Biotechnology), the monoclonal anti- $\alpha$-Actinin IgG1 antibody (Sigma), and anti-Affixin IgG antibody (Yamaji et al. 2001). Secondary antibodies included goat anti-mouse IgG2b-TRITC and goat antimouse IgG1-FITC antibodies (Southern Biotech), and anti-rabbit IgG-TRITC (Sigma) antibody and anti-rabbit IgG-FITC (Molecular Probes) antibody.

\section{Genetic mapping, positional cloning, and mutation detection}

DNA from $24 \mathrm{msq}$ mutant and 24 wild-type embryos was pooled, and bulked segregation analysis was performed as described (Michelmore et al. 1991). The critical genomic interval for $m s q$ was defined by genotyping 1674 mutant embryos for polymorphic markers in the area. RNA from msq mutant and wild-type embryos was isolated using TRIZOL Reagent (Life Technologies) and reverse-transcribed. Four independent clones from mutant and wild-type zmsq cDNA were sequenced. Genomic DNA from $m s q$ mutant and wild-type embryos was sequenced around the point mutation.

\section{Injection procedures}

Morpholino-modified oligonucleotides were directed against the translational start site (MO1-zilk, 5'-GGCACTGAGTGAAGAT GTCATCCAT-3') and the splice donor site of exon 4 of zilk (MO2-zilk, 5'-GAGAGTGCTTACCTTTTAGATTTGC-3'). The $\beta$-parvin (affixin) morpholino was directed against the splice donor site of exon 5 (MO-zafx, 5'-TGTTTTGGCCGCTTA CAGTCGACAC-3'; MO2-zafx, 5'-TGGCCGCTTACAGTCGACACTCCAC-3'). A standard control morpholino antisense oligonucleotide (MO-control; Genetools, LLC) was injected at the same concentrations.

Sense-capped RNA was synthesized using the mMESSAGE mMASCHINE system (Ambion) for hilk constructs ILK ${ }^{\mathrm{R} 211 \mathrm{~A}}$ and ILK ${ }^{\mathrm{E} 359 \mathrm{~K}}$, the PKB constructs myrPKB and inactPKB, and pCMV zilk ${ }^{\mathrm{wt}}$ and zilk $^{\mathrm{L} 308 \mathrm{P}}$. RNA was diluted $(15,30,50$, or 80 $\mathrm{ng} / \mathrm{\mu L}$ in solution $\mathrm{A}[0.1 \%$ phenol red, $0.2 \mathrm{M} \mathrm{KCl}])$ and microinjected into one-cell-stage embryos. Siblings from the same pool were injected using solution A as control.

\section{Expression and purification of recombinant ILK}

The $m s q^{\mathrm{L} 308 \mathrm{P}}$ mutation was introduced into hilk by PCR-mutagenesis. hilk ${ }^{w t}$, hilk ${ }^{\mathrm{L} 308 \mathrm{P}}$, hafx, and $h p x n$ were amplified by PCR and subcloned into the pCDNA3.1 vector (Invitrogen). For expression of zebrafish GST fusion proteins, zilk ${ }^{\mathrm{wt}}$ and $z$ ilk $^{\mathrm{L} 308 \mathrm{P}}$ were amplified by PCR and subcloned in to the pGEX6P-1 vector (Amersham). GST-zILK fusion proteins were expressed in Escherichia coli BL21 DE3 by inducing bacteria with $1 \mathrm{mM}$ IPTG for $6 \mathrm{~h}$ at $16^{\circ} \mathrm{C}$. Bacteria were harvested by centrifugation and resuspended in extraction buffer $(300 \mathrm{mM} \mathrm{NaCl}, 50 \mathrm{mM}$ Tris/HCl at $\mathrm{pH} 7.5,1 \mathrm{mM}$ DTT, $5 \mathrm{mM}$ EDTA, $5 \mathrm{mM}$ EGTA, 0.01\% IgePal, and protease inhibitors Leupeptin, PepstatinA, Aprotenin $[10 \mu \mathrm{g} / \mathrm{mL}$ each $]$, and AEBSF $[0.1 \mathrm{mM}])$. Bacterial cells were disrupted by sonification, and cell debris was removed by centrifugation $\left(35,000 \mathrm{rpm}, 30 \mathrm{~min}, 4^{\circ} \mathrm{C}\right)$. GST fusion proteins were purified with glutathione-Sepharose matrix (Amersham) as described by the manufacturer.

\section{In vitro kinase assay}

To test for kinase activity of zILK, glutathione-Sepharose-immobilized kinase was incubated with $2 \mu \mathrm{g}$ of dephosphorylated MBP (Upstate Biotechnology). Incubations were carried out with $10 \mu \mathrm{Ci}$ of $\left[{ }^{32} \mathrm{P}\right]-\gamma \mathrm{ATP}$ at $30^{\circ} \mathrm{C}$ for $1 \mathrm{~h}$ in kinase buffer containing $20 \mathrm{mM}$ HEPES (pH 7.5), $5 \mathrm{mM} \mathrm{MgCl}_{2}, 1 \mathrm{mM} \mathrm{MnCl}_{2}$, $0.05 \%$ NP-40, $7.15 \mathrm{mM} \beta$-mercaptoethanole, $125 \mathrm{mM} \mathrm{Na-or-}$ tho-vanadate, and protease inhibitors Leupeptin, PepstatinA, Aprotenin $(0.1 \mu \mathrm{g} / \mathrm{mL}$ each), and AEBSF (0.01 mM). Kinase reaction was terminated by twofold SDS-sample buffer. Phosphorylated proteins were separated by SDS-PAGE and detected by autoradiography of the dried gel. $\left[{ }^{32} \mathrm{P}\right]$ incorporation was quantified using a Fujifilm BAS-2500 PhosphorImager.

In vitro translation of proteins and in vitro coimmunoprecipitations

$\left[{ }^{35} \mathrm{~S}\right]-$ Methionine-labeled hILK ${ }^{\mathrm{wt}}$ or hILK ${ }^{\mathrm{L} 308 \mathrm{P}}$ was cotranslated with HA-tagged hAfx, hPxn, or hp27 Kip1, respectively, using a TNT-T7 Quick Coupled Transcription/Translation System reaction (Promega). HA-tagged proteins were immunoprecipitated with HA-antibody HA.11 (Babco), immobilized to protein A Sepharose (Sigma). The resin was washed three times with buffer containing $250 \mathrm{mM} \mathrm{NaCl}, 50 \mathrm{mM}$ Tris, $1 \mathrm{mM}$ EDTA, and $0.01 \%$ IgePal ( $\mathrm{pH}$ 7.5). Bound proteins were eluted by boiling in twofold SDS sample buffer and separated by SDS-PAGE. Proteins were visualized by Coomassie staining, and radiolabled proteins were detected by autoradiography of the dried gel.

\section{Acknowledgments}

We thank S. Marquart and H. Hosser for excellent technical assistance, and A. Doherty for her support in fish care and breeding. We thank S. Dedhar for kindly providing hilk ${ }^{w t}$, hilk ${ }^{E 359 K}$, and hilk ${ }^{R 211 A} ; \mathrm{J}$. Chan for supplying us with the PKB constructs 
myrPBK and inactPBK; and S. Yamaji for the anti- $\beta$-parvin (Affixin) antibody. M.G. is grateful to U. Fischer for continuous support and helpful discussions. This work was supported by grants from NIH-5R01HL49579, 5R01DK55383, 1R01HL63206 (to M.C.F.), DFG Ro2173/1-1, DFG Ro2173/2-1, and BMBF 01GS0420, as well as Klaus-Georg and Sigrid Hengstberger Stipendium (to W.R.), and the Postdoc-Fellowship of the medical faculty of the University of Heidelberg (to I.G.H. and T.D.).

\section{References}

Attwell, S., Mills, J., Troussard, A., Wu, C., and Dedhar, S. 2003. Integration of cell attachment, cytoskeletal localization, and signaling by integrin-linked kinase (ILK), CH-ILKBP, and the tumor suppressor PTEN. Mol. Biol. Cell 14: 4813-4825.

Bock-Marquette, I., Saxena, A., White, M.D., Dimaio, J.M., and Srivastava, D. 2004. Thymosin $\beta 4$ activates integrin-linked kinase and promotes cardiac cell migration, survival and cardiac repair. Nature 432: 466-472.

Brancaccio, M., Fratta, L., Notte, A., Hirsch, E., Poulet, R., Guazzone, S., De Acetis, M., Vecchione, C., Marino, G., Altruda, F., et al. 2003. Melusin, a muscle-specific integrin $\beta 1$-interacting protein, is required to prevent cardiac failure in response to chronic pressure overload. Nat. Med. 9: 68-75.

Burggren, W.W. and Pinder, A.W. 1991. Ontogeny of cardiovascular and respiratory physiology in lower vertebrates. Annu. Rev. Physiol. 53: 107-135.

Chan, J., Bayliss, P.E., Wood, J.M., and Roberts, T.M. 2002. Dissection of angiogenic signaling in zebrafish using a chemical genetic approach. Cancer Cell 1: 257-267.

De Acetis, M., Notte, A., Accornero, F., Selvetella, G., Brancaccio, M., Vecchione, C., Sbroggio, M., Collino, F., Pacchioni, B., Lanfranchi, G., et al. 2005. Cardiac overexpression of melusin protects from dilated cardiomyopathy due to longstanding pressure overload. Circ. Res. 96: 1087-1094.

Dedhar, S. 2000. Cell-substrate interactions and signaling through ILK. Curr. Opin. Cell Biol. 12: 250-256.

Delcommenne, M., Tan, C., Gray, V., Rue, L., Woodgett, J., and Dedhar, S. 1998. Phosphoinositide-3-OH kinase-dependent regulation of glycogen synthase kinase 3 and protein kinase B/AKT by the integrin-linked kinase. Proc. Natl. Acad. Sci. 95: 11211-11216.

Dimmeler, S., Assmus, B., Hermann, C., Haendeler, J., and Zeiher, A.M. 1998. Fluid shear stress stimulates phosphorylation of Akt in human endothelial cells: Involvement in suppression of apoptosis. Circ. Res. 83: 334-341.

Friedrich, E.B., Liu, E., Sinha, S., Cook, S., Milstone, D.S., MacRae, C.A., Mariotti, M., Kuhlencordt, P.J., Force, T., Rosenzweig, A., et al. 2004. Integrin-linked kinase regulates endothelial cell survival and vascular development. Mol. Cell. Biol. 24: 8134-8144.

Fukuda, T., Guo, L., Shi, X., and Wu, C. 2003. CH-ILKBP regulates cell survival by facilitating the membrane translocation of protein kinase B/Akt. J. Cell Biol. 160: 1001-1008.

Guo, L. and Wu, C. 2002. Regulation of fibronectin matrix deposition and cell proliferation by the PINCH-ILK-CH-ILKBP complex. FASEB T. 16: 1298-1300.

Hannigan, G.E., Leung-Hagesteijn, C., Fitz-Gibbon, L., Coppolino, M.G., Radeva, G., Filmus, J., Bell, J.C., and Dedhar, S. 1996. Regulation of cell adhesion and anchorage-dependent growth by a new $\beta$ 1-integrin-linked protein kinase. Nature 379: 91-96.

Hongo, M., Ryoke, T., Schoenfeld, J., Hunter, J., Dalton, N., Clark, R., Lowe, D., Chien, K., and Ross Jr., J. 2000. Effects of growth hormone on cardiac dysfunction and gene expression in genetic murine dilated cardiomyopathy. Basic Res. Cardiol. 95: 431-441.

Jowett, T. and Lettice, L. 1994. Whole-mount in situ hybridizations on zebrafish embryos using a mixture of digoxigeninand fluorescein-labelled probes. Trends Genet. 10: 73-74.

Keller, R.S., Shai, S.Y., Babbitt, C.J., Pham, C.G., Solaro, R.J., Valencik, M.L., Loftus, J.C., and Ross, R.S. 2001. Disruption of integrin function in the murine myocardium leads to perinatal lethality, fibrosis, and abnormal cardiac performance. Am. J. Pathol. 158: 1079-1090.

Kim, C.H., Cho, Y.S., Chun, Y.S., Park, J.W., and Kim, M.S. 2002. Early expression of myocardial HIF-1 $\alpha$ in response to mechanical stresses: Regulation by stretch-activated channels and the phosphatidylinositol 3-kinase signaling pathway. Circ. Res. 90: E25-E33.

Lee, G., Abdi, K., Jiang, Y., Michaely, P., Bennett, V., and Marszalek, P.E. 2006. Nanospring behaviour of ankyrin repeats. Nature 440: 246-249.

Legate, K.R., Montanez, E., Kudlacek, O., and Fassler, R. 2006. ILK, PINCH and parvin: The tIPP of integrin signalling. Nat. Rev. Mol. Cell Biol. 7: 20-31.

Li, F., Zhang, Y., and Wu, C. 1999. Integrin-linked kinase is localized to cell-matrix focal adhesions but not cell-cell adhesion sites and the focal adhesion localization of integrinlinked kinase is regulated by the PINCH-binding ANK repeats. J. Cell Sci. 112: 4589-4599.

Mackinnon, A.C., Qadota, H., Norman, K.R., Moerman, D.G., and Williams, B.D. 2002. C. elegans PAT-4/ILK functions as an adaptor protein within integrin adhesion complexes. Curr. Biol. 12: 787-797.

Michelmore, R.W., Paran, I., and Kesseli, R.V. 1991. Identification of markers linked to disease-resistance genes by bulked segregant analysis: A rapid method to detect markers in specific genomic regions by using segregating populations. Proc. Natl. Acad. Sci. 88: 9828-9832.

Miller, M.G., Naruszewicz, I., Kumar, A.S., Ramlal, T., and Hannigan, G.E. 2003. Integrin-linked kinase is a positive mediator of L6 myoblast differentiation. Biochem. Biophys. Res. Commun. 310: 796-803.

Morisco, C., Zebrowski, D., Condorelli, G., Tsichlis, P., Vatner, S.F., and Sadoshima, J. 2000. The Akt-glycogen synthase kinase $3 \beta$ pathway regulates transcription of atrial natriuretic factor induced by $\beta$-adrenergic receptor stimulation in cardiac myocytes. J. Biol. Chem. 275: 14466-14475.

Nho, R.S., Xia, H., Kahm, J., Kleidon, J., Diebold, D., and Henke, C.A. 2005. Role of integrin-linked kinase in regulating phosphorylation of Akt and fibroblast survival in type I collagen matrices through a $\beta 1$ integrin viability signaling pathway. J. Biol. Chem. 280: 26630-26639.

Novak, A., Hsu, S.C., Leung-Hagesteijn, C., Radeva, G., Papkoff, J., Montesano, R., Roskelley, C., Grosschedl, R., and Dedhar, S. 1998. Cell adhesion and the integrin-linked kinase regulate the LEF-1 and $\beta$-catenin signaling pathways. Proc. Natl. Acad. Sci. 95: 4374-4379.

Pan, J., Fukuda, K., Saito, M., Matsuzaki, J., Kodama, H., Sano, M., Takahashi, T., Kato, T., and Ogawa, S. 1999. Mechanical stretch activates the JAK/STAT pathway in rat cardiomyocytes. Circ. Res. 84: 1127-1136.

Persad, S., Attwell, S., Gray, V., Delcommenne, M., Troussard, A., Sanghera, J., and Dedhar, S. 2000. Inhibition of integrinlinked kinase (ILK) suppresses activation of protein kinase B/Akt and induces cell cycle arrest and apoptosis of PTENmutant prostate cancer cells. Proc. Nat1. Acad. Sci. 97: 3207-3212.

Persad, S., Attwell, S., Gray, V., Mawji, N., Deng, J.T., Leung, D., Yan, J., Sanghera, J., Walsh, M.P., and Dedhar, S. 2001a. 
Bendig et al.

Regulation of protein kinase B/Akt-serine 473 phosphorylation by integrin-linked kinase: Critical roles for kinase activity and amino acids arginine 211 and serine 343. J. Biol. Chem. 276: 27462-27469.

Persad, S., Troussard, A.A., McPhee, T.R., Mulholland, D.J., and Dedhar, S. 2001b. Tumor suppressor PTEN inhibits nuclear accumulation of $\beta$-catenin and $T$ cell/lymphoid enhancer factor 1-mediated transcriptional activation. J. Cell Biol. 153: $1161-1174$.

Petroff, M.G., Kim, S.H., Pepe, S., Dessy, C., Marban, E., Balligand, J.L., and Sollott, S.J. 2001. Endogenous nitric oxide mechanisms mediate the stretch dependence of $\mathrm{Ca}^{2+}$ release in cardiomyocytes. Nat. Cell Biol. 3: 867-873.

Rottbauer, W., Baker, K., Wo, Z.G., Mohideen, M.A., Cantiello, H.F., and Fishman, M.C. 2001. Growth and function of the embryonic heart depend upon the cardiac-specific L-type calcium channel $\alpha 1$ subunit. Dev. Cell 1: 265-275.

Rottbauer, W., Saurin, A.J., Lickert, H., Shen, X., Burns, C.G., Wo, Z.G., Kemler, R., Kingston, R., Wu, C., and Fishman, M.C. 2002. Reptin and pontin antagonistically regulate heart growth in zebrafish embryos. Cell 111: 661-672.

Rottbauer, W., Just, S., Wessels, G., Trano, N., Most, P., Katus, H.A., and Fishman, M.C. 2005. VEGF-PLC $\gamma 1$ pathway controls cardiac contractility in the embryonic heart. Genes \& Dev. 19: 1624-1634.

Rottbauer, W., Wessels, G., Dahme, T., Just, S., Trano, N., Hassel, D., Burns, C.G., Katus, H.A., and Fishman, M.C. 2006. Cardiac myosin light chain-2. A novel essential component of thick-myofilament assembly and contractility of the heart. Circ. Res. (in press).

Sakai, T., Li, S., Docheva, D., Grashoff, C., Sakai, K., Kostka, G., Braun, A., Pfeifer, A., Yurchenco, P.D., and Fassler, R. 2003. Integrin-linked kinase (ILK) is required for polarizing the epiblast, cell adhesion, and controlling actin accumulation. Genes \& Dev. 17: 926-940.

Samarel, A.M. 2005. Costameres, focal adhesions, and cardiomyocyte mechanotransduction. Am. J. Physiol. Heart Circ. Physiol. 289: H2291-H2301.

Sedding, D.G., Hermsen, J., Seay, U., Eickelberg, O., Kummer, W., Schwencke, C., Strasser, R.H., Tillmanns, H., and BraunDullaeus, R.C. 2005. Caveolin-1 facilitates mechanosensitive protein kinase B (Akt) signaling in vitro and in vivo. Circ. Res. 96: 635-642.

Sehnert, A.J., Huq, A., Weinstein, B.M., Walker, C., Fishman, M., and Stainier, D.Y. 2002. Cardiac troponin T is essential in sarcomere assembly and cardiac contractility. Nat. Genet. 31: 106-110.

Seko, Y., Takahashi, N., Shibuya, M., and Yazaki, Y. 1999. Pulsatile stretch stimulates vascular endothelial growth factor (VEGF) secretion by cultured rat cardiac myocytes. Biochem. Biophys. Res. Commun. 254: 462-465.

Shai, S.Y., Harpf, A.E., Babbitt, C.J., Jordan, M.C., Fishbein, M.C., Chen, J., Omura, M., Leil, T.A., Becker, K.D., Jiang, M., et al. 2002. Cardiac myocyte-specific excision of the $\beta 1$ integrin gene results in myocardial fibrosis and cardiac failure. Circ. Res. 90: 458-464.

Stainier, D.Y. and Fishman, M.C. 1994. The zebrafish as an model system to study cardiovascular development. Trends Cardiovasc. Med. 4: 207-212.

Stainier, D.Y., Fouquet, B., Chen, J.N., Warren, K.S., Weinstein, B.M., Meiler, S.E., Mohideen, M.A., Neuhauss, S.C., SolnicaKrezel, L., Schier, A.F., et al. 1996. Mutations affecting the formation and function of the cardiovascular system in the zebrafish embryo. Development 123: 285-292.

Starling, E.H. 1918. Linacre lecture on the law of the heart. Longmans, Green and Co., London.
Tan, C., Cruet-Hennequart, S., Troussard, A., Fazli, L., Costello, P., Sutton, K., Wheeler, J., Gleave, M., Sanghera, J., and Dedhar, S. 2004. Regulation of tumor angiogenesis by integrin-linked kinase (ILK). Cancer Cell 5: 79-90.

Wu, C. and Dedhar, S. 2001. Integrin-linked kinase (ILK) and its interactors: A new paradigm for the coupling of extracellular matrix to actin cytoskeleton and signaling complexes. J. Cell Biol. 155: 505-510.

Xu, X., Meiler, S.E., Zhong, T.P., Mohideen, M., Crossley, D.A., Burggren, W.W., and Fishman, M.C. 2002. Cardiomyopathy in zebrafish due to mutation in an alternatively spliced exon of titin. Nat. Genet. 30: 205-209.

Yamaji, S., Suzuki, A., Sugiyama, Y., Koide, Y., Yoshida, M., Kanamori, H., Mohri, H., Ohno, S., and Ishigatsubo, Y. 2001. A novel integrin-linked kinase-binding protein, affixin, is involved in the early stage of cell-substrate interaction. $J$. Cell Biol. 153: 1251-1264.

Zervas, C.G., Gregory, S.L., and Brown, N.H. 2001. Drosophila integrin-linked kinase is required at sites of integrin adhesion to link the cytoskeleton to the plasma membrane. $J$. Cell Biol. 152: 1007-1018.

Zhang, Y., Guo, L., Chen, K., and Wu, C. 2002. A critical role of the PINCH-integrin-linked kinase interaction in the regulation of cell shape change and migration. J. Biol. Chem. 277: 318-326. 


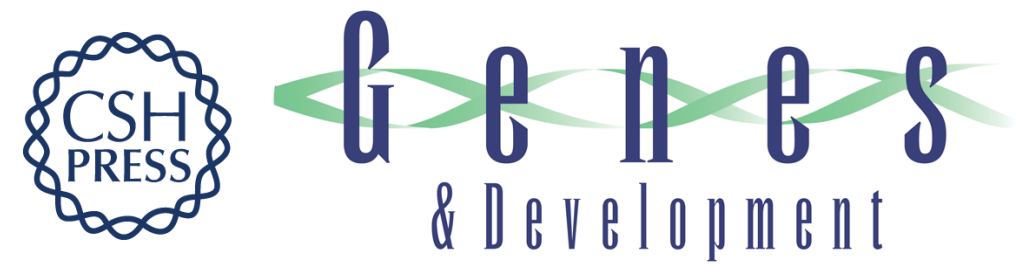

\section{Integrin-linked kinase, a novel component of the cardiac mechanical stretch sensor, controls contractility in the zebrafish heart}

Garnet Bendig, Matthias Grimmler, Inken G. Huttner, et al.

Genes Dev. 2006, 20:

Access the most recent version at doi:10.1101/gad.1448306

\section{Supplemental http://genesdev.cshlp.org/content/suppl/2006/09/07/gad.1448306.DC1 \\ Material}

Related Content Stretching to meet needs: integrin-linked kinase and the cardiac pump Deepak Srivastava and Sangho $\mathrm{Yu}$

Genes Dev. September , 2006 20: 2327-2331

References This article cites 46 articles, 24 of which can be accessed free at: http://genesdev.cshlp.org/content/20/17/2361.full.html\#ref-list-1

Articles cited in:

http://genesdev.cshlp.org/content/20/17/2361.full.html\#related-urls

\section{License}

Email Alerting

Service

Receive free email alerts when new articles cite this article - sign up in the box at the top right corner of the article or click here.

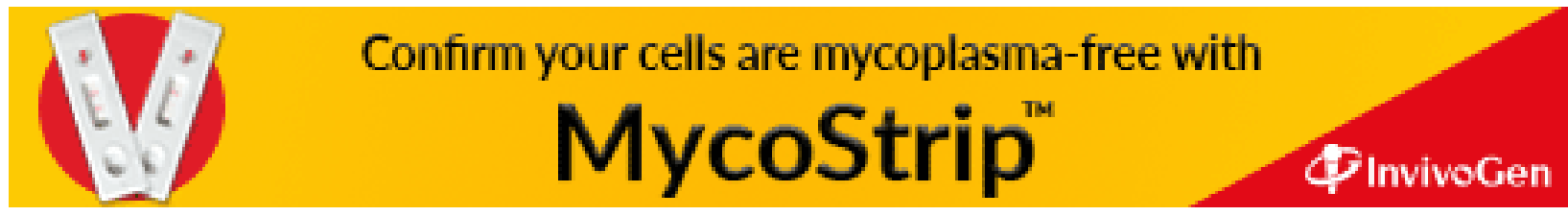

